\title{
Tailings dam safety: going beyond technical
}

\author{
C Priscu Anglo American, Canada
}

\begin{abstract}
The criticality of effective stewardship of tailings facilities has recently gained increasing recognition and triggered much effort on the part of the many mining companies across the world. The world of mining, and in particular the mine waste management practice area, is changing dramatically after the recent tragic events following the tailings dam failure in Brazil in January 2019. Investors, communities, shareholders, non-governmental organisations, regulators and insurance companies are looking to the tailings storage facilities and their management through a completely different lens; one that focuses on the need for implementing best available practices (BAP), best applicable technologies (BAT), and how the zero repeats commitment of the mining industry will be achieved.
\end{abstract}

This presentation outlines Anglo American's approach to building a world-class tailings storage facilities practice, which includes a number of key must-have ingredients:

1. A solid and strict governance framework for the oversight of a large portfolio of tailings and water dams in a global environment, where stringent minimum technical standards are implemented with non-negotiable requirements.

2. The need for people with the right set of skills, competencies, and technical knowledge, but also the mindset on safety and the 'do the right thing' approach that needs to be part of their DNA.

3. The critical controls definition and implementation to ensure each facility is planned, built and managed safely to design requirements, minimising the presence of the 'surprise' effect, and in particular the minimisation of the human error element factor.

4. Pushing the boundaries of technology and innovation in tailings production, deposition, and management of such facilities. From minimising the tailings production, to high tech near real-time monitoring instrumentation and surveillance technologies, all are key ingredients in building a global success story.

Implementing the Anglo American dam safety management program at a global level does not come without challenges. The presentation will discuss the strategy and share some of the success stories, as well as lessons learned along the Anglo American journey since 2014, when the company transformed its internal technical requirements, raising the bar to a whole new level.

Keywords: dam safety, governance, dam monitoring, dam surveillance, tailings dam, tailings management 
